\title{
Use of health services: Baseline findings
}

Population Council

Follow this and additional works at: https://knowledgecommons.popcouncil.org/departments_sbsr-pgy

Part of the Demography, Population, and Ecology Commons, Family, Life Course, and Society Commons, Gender and Sexuality Commons, and the International Public Health Commons How does access to this work benefit you? Let us know!

\section{Recommended Citation}

"Use of health services: Baseline findings," AGEP brief. Lusaka: Population Council, 2015. 
The Adolescent Girls Empowerment Program (AGEP) is a program for girls ages 10-19 in rural and urban Zambia that aims to find the best ways to improve their social, health, and economic resources. The program involves over 10,000 girls participating in weekly girls' group meetings, receiving health vouchers and opening savings accounts. Over 5,000 girls, unmarried at baseline, are enrolled in a randomized, controlled trial and are being followed over four years-including the two years of the program and two years after. This brief describes the use of health services by these girls at baseline.

\section{INTRODUCTION}

While adolescence is generally a time of good health, girls still have health needs related to both general wellness and sexual and reproductive health (SRH).

In partnership with the Zambia Ministry of Community Development, Mother and Child Health, The Adolescent Girls Empowerment Program (AGEP) is testing methods of increasing use of health services through a voucher, redeemable for health services at certain public and private health providers. The services covered by the voucher include basic wellness exams and ageappropriate sexual and reproductive health services.

\section{Self-reported health}

The girls in the AGEP study consider themselves to be in good health on average. On a scale of 1 to 10 , where $1=$ "Very Bad" and $10=$ "Very Good," the mean score for self-reported health in the past year was 8.1.

\section{Insurance}

Very few respondents (less than 2\%) had health insurance coverage. Another small group (11\%) did not know whether they had health insurance. Compared to those ages 15-19, a higher percentage of those ages 10-14 did not know whether they had health insurance (16\% vs. $7 \%)$.

The Population Council conducts research and delivers solutions that improve lives around the world. Big ideas supported by evidence: It's our model for global change. popcouncil.org (C) 2015 The Population Council, Inc.

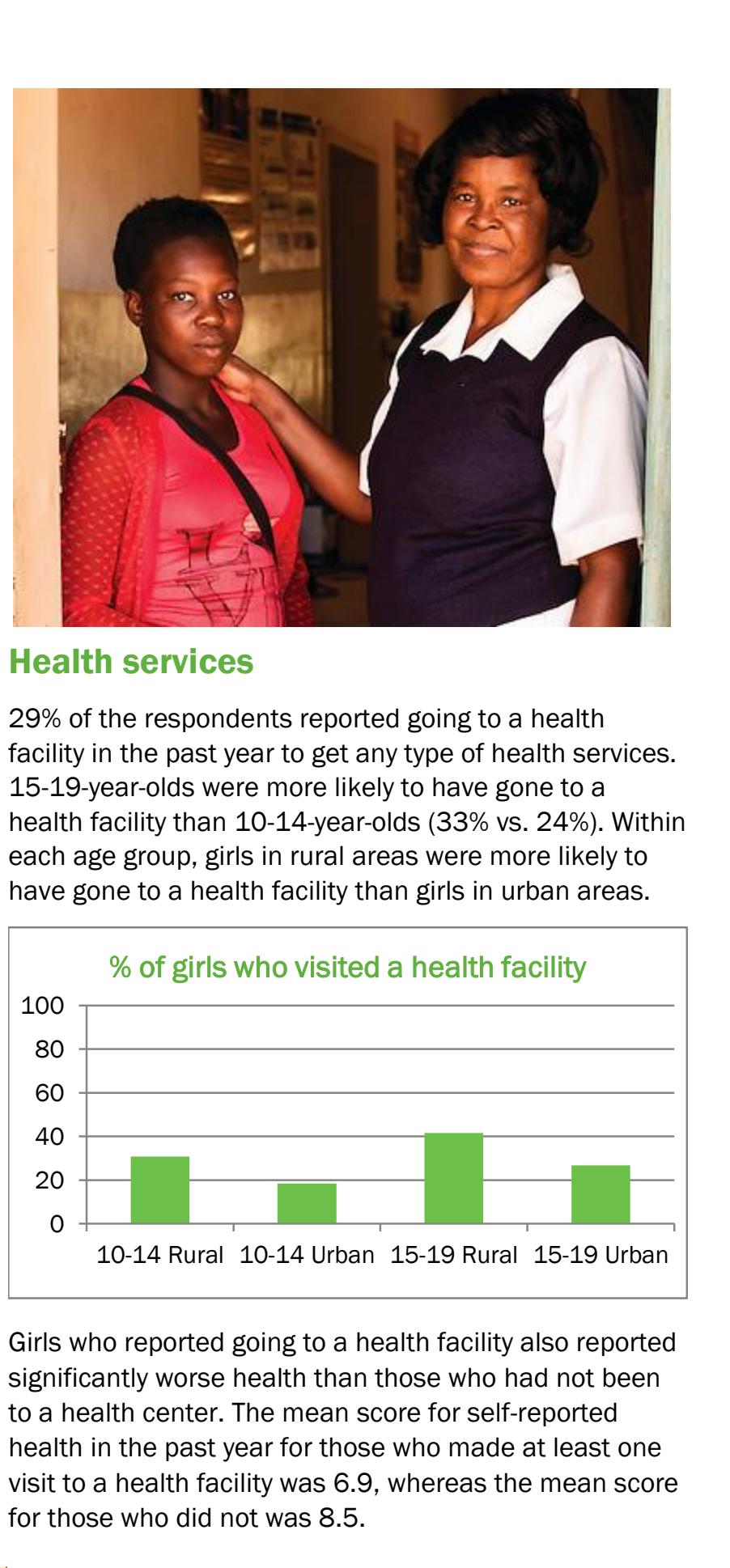

\section{Health services}

$29 \%$ of the respondents reported going to a health facility in the past year to get any type of health services. 15-19-year-olds were more likely to have gone to a health facility than $10-14$-year-olds (33\% vs. $24 \%$ ). Within each age group, girls in rural areas were more likely to have gone to a health facility than girls in urban areas.

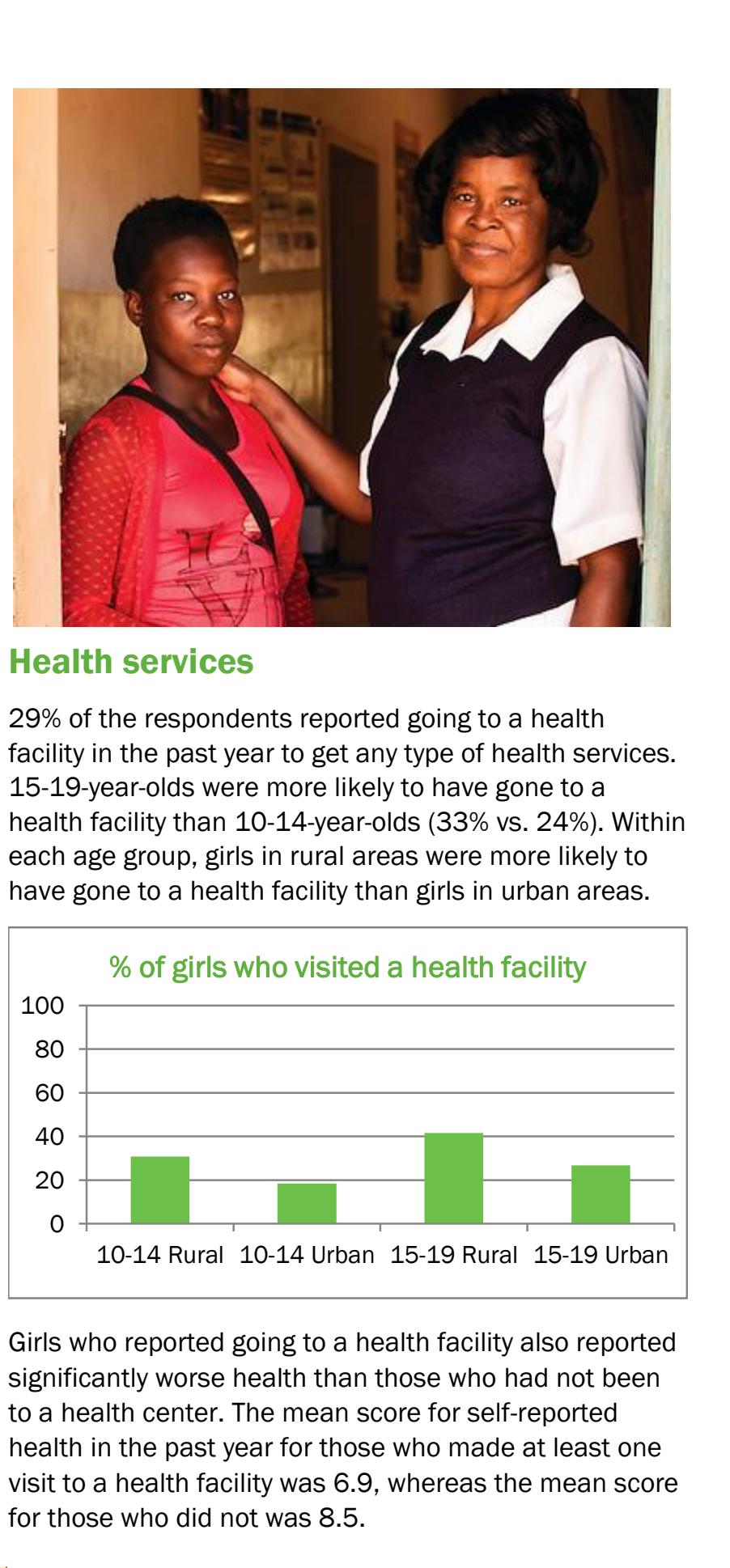

Girls who reported going to a health facility also reported significantly worse health than those who had not been to a health center. The mean score for self-reported health in the past year for those who made at least one visit to a health facility was 6.9 , whereas the mean score for those who did not was 8.5.

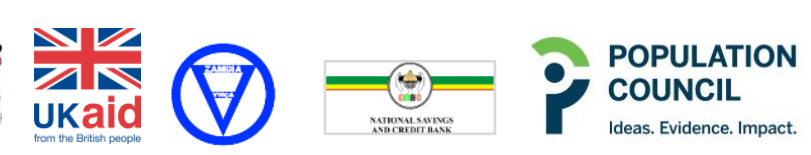


For both age groups, public health clinics were the most common type of health facility visited in both urban and rural areas. In urban areas, the second most common type of health facility was a public hospital. In rural areas, the second most common type of health facility was a mission or private hospital.

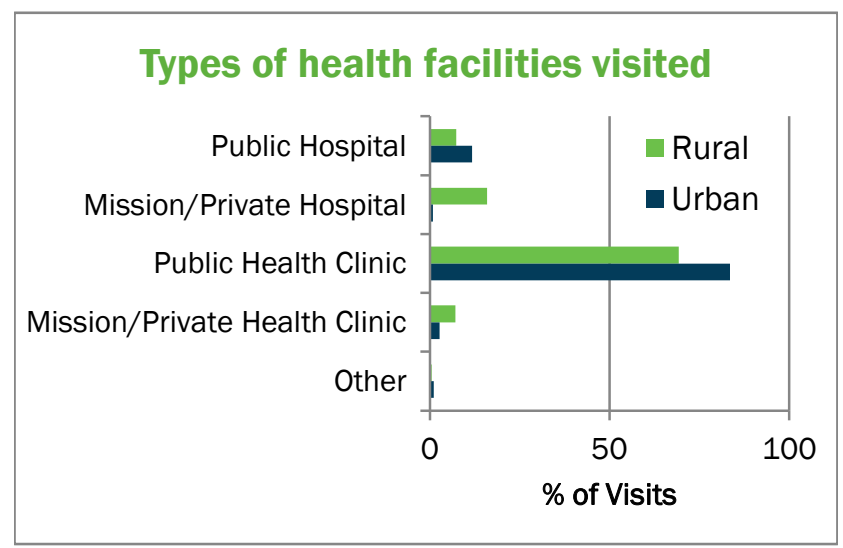

The primary purpose for the majority of these visits was to seek care for general health/sickness (83\%). The next most common service sought was antenatal care (5\%). At almost all visits, girls received the services for which they came (93\%).

\section{Barriers to seeking care}

Respondents were asked to state whether certain factors were or were not barriers to seeking medical advice or treatment when they were ill.

The main concern for younger girls in both urban and rural areas was not wanting to go alone. In contrast, the main concern for older urban girls was lack of medications, and for older rural girls it was distance. Rural girls of all ages considered distance and transport barriers far more than urban girls did.

\section{DISCUSSION}

Less than one-third of girls visited a health facility in the past year; adolescence is generally a time of good health. However, those who considered themselves to have poor health in the past year were more likely to have visited a health facility, indicating appropriate care-seeking behavior. Girls in rural areas were more likely to visit health facilities than were girls in urban areas, which may indicate that the urban girls in the AGEP study are in better health than girls in rural areas, or it may mean that they are more vulnerable. The barriers identified by respondents do not explain why urban girls were less likely to visit health facilities. Further investigation into this is warranted to determine whether urban girls are not seeking care in situations they should be, whether there are other barriers to accessing care in urban areas not delineated in this study, or whether there are differences in the health of the population in urban and rural areas that account for this difference that are unidentified here. AGEP will seek to answer these questions, in addition to understanding the impact of the health voucher on use of health services, in future rounds of data analysis.

This program is funded by UKaid from the Department for International Development.

\begin{tabular}{|c|c|c|c|c|}
\hline \multirow[t]{2}{*}{ Barriers to Healthcare } & \multicolumn{3}{|c|}{$\%$ of gills } & \multirow[b]{2}{*}{$\begin{array}{l}15-19 \\
\text { Urban }\end{array}$} \\
\hline & $\begin{array}{r}10-14 \\
\text { Rural }\end{array}$ & $\begin{array}{l}10-14 \\
\text { Urban }\end{array}$ & $\begin{array}{r}15-19 \\
\text { Rural }\end{array}$ & \\
\hline Not wanting to go alone & 38.2 & 25.9 & 27.7 & 17.4 \\
\hline The distance to the health facility & 36.5 & 12.7 & 34.3 & 13.9 \\
\hline Having to take transport & 27.7 & 11.4 & 28 & 13.4 \\
\hline Getting money needed for treatment & 18.7 & 17.7 & 19.6 & 16.6 \\
\hline Concern that there may be no drugs available & 13.3 & 12 & 12.2 & 18.1 \\
\hline Concern that there may not be a female health provider & 12.2 & 8.7 & 12.5 & 9.8 \\
\hline Concern that there may not be any health provider & 9 & 6.7 & 9.5 & 8.9 \\
\hline Getting permission to go & 5.6 & 5.7 & 4.6 & 4.7 \\
\hline
\end{tabular}

\section{CONTACT INFORMATION}

For more information about AGEP, call +260 211295925

or email agep@popcouncil.org

or visit: http://www.popcouncil.org/research/

adolescent-girls-empowerment-program
Population Council

Plot \#3670 No. 4 Mwaleshi Road

Olympic Park

Lusaka, Zambia 10101 